\title{
Sodium-Calcium and Sodium-Magnesium Exchange on Wyoming Bentonite in Perchlorate and Chloride Background Ionic Media ${ }^{1}$
}

\author{
Garrison Sposito, Kenneth M. Holtzclaw, Laurent Charlet, Claire Jouany, and A. L. Page²
}

\section{ABSTRACT}

The exchange of calcium and magnesium for sodium at $298 \mathrm{~K}$ on Wyoming bentonite was investigated in perchlorate and chloride background media maintained at $\mathrm{pH} 7.0$ and at a total cation normality of $0.05 N$. In the perchlorate medium, the apparent total adsorbed metal charge was independent of the exchanger composition and equal to 0.97 $\pm 0.06 \mathrm{~mol}_{\mathrm{c}} \mathrm{kg}^{-1}$ (average for $\mathrm{Na}-\mathrm{Ca}$ and $\mathrm{Na}-\mathrm{Mg}$ exchanges). In the chloride medium, the apparent total adsorbed metal charge increased with the amount of calcium or magnesium adsorbed, tending to a value near $1.3 \mathrm{~mol}_{\mathrm{c}} \mathrm{kg}^{-1}$ as the clay became saturated with the bivalent metal cation. These results were interpreted as evidence for the adsorption of $\mathrm{CaCl}^{+}$or $\mathrm{MgCl}^{+}$complexes in the exchange experiments conducted in the chloride medium. A detailed analysis of the exchange data led to the conclusion that a Ca-montmorillonite or $\mathrm{Mg}$-montmorillonite suspension in a chloride background consists of quasicrystals with bivalent cations adsorbed on the internal surfaces and monovalent metal-chloride complexes adsorbed on the external surfaces.

Additional Index Words: cation exchange, chloride complexes, speciation of adsorbed metals.

Sposito, G., K. M. Holtzclaw, L. Charlet, C. Jouany, and A. L. Page. 1983. Sodium-calcium and sodium-magnesium exchange on Wyoming bentonite in perchlorate and chloride background ionic media. Soil Sci Soc. Am. J. 47:51-56.

$\mathrm{A}^{\mathrm{N}}$ $\mathrm{N}$ INTERESTING LEITMOTIV pertaining to surface charge and adsorption selectivity emerges from an examination of the published literature concerning unibivalent cation exchange on montmorillonite or in montmorillonitic soils. The data reveal that, as a general rule, an increase in the number of bivalent metal cations on the exchanger, toward complete saturation, produces corresponding increases in both the apparent total adsorbed metal charge and the selectivity of the exchanger for the bivalent metal cation. Thus, as the aqueous solution bathing a montmorillonite exchanger is enriched in the bivalent metal cation that replaces an adsorbed alkali

\footnotetext{
'Contribution from the Dep. of Soil and Environmental Sciences, University of California, Riverside, CA 92521 . Received 14 July 1982. Approved 27 Sept. 1982.

2 Professor of Soil Science, Research Associate IV, Graduate Research Assistant, Visiting Postdoctoral Fellow, and Professor of Soil Science, respectively.
} 
metal cation, the apparent cation exchange capacity (CEC) and the exchange selectivity coefficient for this replacement both are observed to grow larger (Schwertmann, 1962; Babcock and Shulz, 1963; Deist and Talibudeen, 1967; Laudelout et al., 1968; Levy and Hillel, 1968; Van Bladel and Menzel, 1969; Van Bladel et al., 1973; Jensen and Babcock, 1973; Jensen, 1973; Maes et al., 1976; Maes and Cremers, 1977; Shainberg et al., 1980; Van Bladel and Gheyi, 1980).

Besides the general trends just described, the studies of uni-bivalent cation exchange cited retain the common feature of having been done in either chloride or nitrate background ionic media. Since it is established now that both $\mathrm{Cl}^{-}$and $\mathrm{NO}_{3}^{-}$can form weak complexes with bivalent metal cations (Smith and Martell, 1976), the question arises as to whether the characteristics of unibivalent cation exchange on montmorillonite would be different if a background medium containing perchlorate ion, which do not form such complexes (Hester and Plane, 1964), were to be used instead. This question was investigated for a specific case by Sposito et al. (1981) in their recent study of sodium-copper exchange on Wyoming bentonite. The results of this study showed that, when the exchange experiment is carried out in a perchlorate ionic medium, neither the total adsorbed metal charge nor the selectivity of the clay for $\mathrm{Cu}^{2+}$ increases as the amount of copper adsorbed is increased. Because the previous research on sodium-copper exchange on montmorillonite had been done in a chloride ionic medium (Maes et al., 1976), Sposito et al. (1981) were led to hypothesize that the complex $\mathrm{CuCl}^{+}$ultimately was responsible for the increases in total adsorbed metal charge and in copper selectivity observed in the earlier study. For example, the apparent increase in total adsorbed metal charge could be attributed to assigning all of the adsorbed $\mathrm{Cu}$ (II) species a valence of $2+$ when in fact one of the adsorbed species was the monovalent complex, $\mathrm{CuCl}^{+}$. This being the case, the increase in $\mathrm{Cu}(\mathrm{II})$ selectivity could be explained if $\mathrm{CuCl}^{+}$was adsorbed by the clay with high affinity.

The hypothesis advanced by Sposito et el. (1981) should be applicable to other previous studies of alkali metalbivalent metal cation exchange on montmorillonite in chloride or nitrate background media. Table 1 lists compiled values of the thermodynamic stability constants for the complexes $\mathrm{MCl}^{+}$and $\mathrm{MNO}_{3}^{+}$, where $\mathrm{M}$ refers to a metal in oxidation state II. The second column of the

Table $1-$ Thermodynamic stability constants $\left(K_{s}\right)$ for the complexes $\mathrm{MCl}^{+}$and $\mathrm{MNO}_{3}{ }^{+}$at $298.15 \mathrm{~K}$ under 1 atm pressure ( $M=$ metal in oxidation state $I I)$.

\begin{tabular}{|c|c|c|}
\hline \multirow[b]{2}{*}{ Metal } & \multicolumn{2}{|c|}{$\log K_{s}$} \\
\hline & $\mathrm{MCl}^{+}$ & $\mathrm{MNO}_{3}{ }^{+}$ \\
\hline Mg(II) & $0.32 \dagger$ & \\
\hline $\mathrm{Ca}(\mathrm{II})$ & $0.42 \dagger$ & $0.7 \ddagger$ \\
\hline $\mathrm{Ba}(\mathrm{HI})$ & $0.46 \dagger$ & $0.9 f$ \\
\hline $\mathrm{Mn}(\mathrm{II})$ & $0.45 \ddagger$ & $0.2 \ddagger$ \\
\hline $\mathrm{Co}(\mathrm{II})$ & $0.36 \ddagger$ & $0.2 \ddagger$ \\
\hline $\mathrm{Ni}(\mathrm{II})$ & $0.41 \ddagger$ & $0.4 \ddagger$ \\
\hline $\mathrm{Cu}(\mathrm{II})$ & $0.40 \ddagger$ & $0.4 \S$ \\
\hline $\mathrm{Zn}(11)$ & $0,43 \ddagger$ & $0.4 \ddagger$ \\
\hline
\end{tabular}

† Johnson $(1979,1981)$.

‡ Smith and Martell (1976); $\log K_{s}$ for $\mathrm{MnCl}^{+}, \mathrm{CoCl}^{*}$, and $\mathrm{NiCl}^{+}$were extrapolated from values of $\log ^{c} K_{s}$ at $1 M$ ionic strength with the Davies equation.

$\S$ Sposito and Holtzclaw (1979). table makes clear the fact that monovalent chloride complexes have essentially the same thermodynamic stability with any bivalent metal cation. Therefore, if $\mathrm{Na}^{+}-\mathrm{Cu}^{2+}$ exchange on montmorillonite is affected by the use of a chloride vs. a perchlorate ionic medium, and if the monovalent complex $\mathrm{MCl}^{+}$is the cause, the same result should hold for $\mathrm{Na}^{+}-\mathrm{Mg}^{2+}$ or $\mathrm{Na}^{+}-\mathrm{Ca}^{2+}$ exchange.

In this paper, the hypothesis of Sposito et al. (1981) will be examined through an investigation of sodiumcalcium and sodium-magnesium exchange on Wyoming bentonite in both perchlorate and chloride ionic media. Data will be presented on the reaction at $25^{\circ} \mathrm{C}$ between Na-saturated Wyoming bentonite and mixed chloride or perchlorate salt solutions maintained near $\mathrm{pH} 7.0$ and at a total cation normality of $0.05 N$. These data will be analyzed to see if they can be interpreted self-consistently on the basis of the hypothesis that the exchange process in chloride background involves the ternary cation system $\mathrm{Na}^{+}-\mathrm{MCl}^{+}-\mathrm{M}^{2+}(\mathrm{M}=\mathrm{Ca}$ or $\mathrm{Mg})$.

\section{MATERIALS AND METHODS}

\section{Na-Montmorillonite}

Montmorillonite clay from Crook County, Wyoming, was obtained from the Source Clays Program repository of the Clay Mineral Society at the University of Missouri for use in the present study. The chemical composition data for this Wyoming bentonite published by Weaver and Pollard (1973, p. 65) lead to the unit cell formula

$\mathrm{M}_{0.62}^{+}\left(\mathrm{Si}_{7.80} \mathrm{Al}_{0.20}\right)\left[\mathrm{Al}_{3.28} \mathrm{Fe}(\mathrm{III})_{0.30} \mathrm{Fe}(\mathrm{II})_{0.04} \mathrm{Mg}_{0.38}\right] \mathrm{O}_{20}(\mathrm{OH})_{4}$,

where $\mathrm{M}^{+}$is a monovalent exchangeable cation. This formula indicates that about one-third of the CEC of the clay derived from isomorphic substitutions originates in the tetrahedral sheet.

The procedures used to purify the clay and prepare it in the sodium-saturated form have been described in detail by Sposito et al. (1981). For the preparation of the Na-montmorillonite employed in exchange experiments involving a chloride background medium, mixed $\mathrm{NaCl} / \mathrm{HCl}$ solutions were used instead of $\mathrm{NaClO}_{4} / \mathrm{HClO}_{4}$ solutions and the clay was stored as a suspension in $0.1 M \mathrm{MaCl}$.

\section{Exchange Experiments}

The Na-montmorillonite samples were reacted at $25.0 \pm$ $0.3^{\circ} \mathrm{C}$ with mixed salt solutions of either $\mathrm{NaClO}_{4} / \mathrm{Ca}\left(\mathrm{ClO}_{4}\right)_{2}$, $\mathrm{NaClO}_{4} / \mathrm{Mg}\left(\mathrm{ClO}_{4}\right)_{2}, \mathrm{NaCl} / \mathrm{CaCl}_{2}$, or $\mathrm{NaCl} / \mathrm{MgCl}_{2}$, maintained at pH 7.0 \pm 0.5 and at a total cation normality of 0.0507 $\pm 0.0035 N$, following the procedure of Sposito et al. (1981). The exchange experiments were carried out in sixfold replication with reaction times varying between 24 and $60 \mathrm{~h}$.

\section{Chemical Analyses}

\section{Clay Concentration}

The concentration of Na-montmorillonite in the stock suspension was determined as described by Sposito et al. (1981). For the three clay stock suspensions prepared in a $\mathrm{ClO}_{4}$ background, the concentrations were $26.0 \pm 0.5,20.98 \pm 0.03$, and $27.51 \pm 0.05 \mathrm{~g}$ of clay $/ \mathrm{kg}$ of suspension. In the case of the two stock suspensions prepared in a $\mathrm{Cl}$ background, $\mathrm{Cl}$ was analyzed with Aminco chloride titrator and the suspension concentrations were $25.69 \pm 0.04$ and $30.9 \pm 0.3 \mathrm{~g}$ of clay $/ \mathrm{kg}$ of suspension.

\section{Supernatant Composition}

Each of the six replicate supernatant solutions in an exchange experiment were analyzed for $\mathrm{Na}$ by flame emission and for either $\mathrm{Ca}$ or $\mathrm{Mg}$ by flame absorption on a Perkin-Elmer Model 
Table 2-Experimental data on $\mathrm{Na}^{+}-\mathrm{Ca}^{2+}$ exchange at $298 \mathrm{~K}$ on Wyoming bentonite in a $0.05 M$ perchlorate background.

\begin{tabular}{|c|c|c|c|c|}
\hline$c_{\mathrm{Na}}$ & $c_{\mathrm{Ca}}$ & $q_{\mathrm{Na}}$ & $q_{\mathrm{Ca}}$ & $Q$ \\
\hline \multicolumn{2}{|c|}{$\mathrm{mol} \mathrm{kg}^{-1} \times 10^{3}-\ldots$} & \multicolumn{3}{|c|}{$-\mathrm{mol}_{c} \mathbf{k g}^{-}$} \\
\hline $50.8 \pm 0.43$ & $<0.01$ & $1.05 \pm 0.23$ & $<0.1$ & 1.05 \\
\hline $52.6 \pm 0.64$ & $0.59 \pm 0.02$ & $0.76 \pm 0.04$ & $0.267 \pm 0.006$ & 1.03 \\
\hline $47.8 \pm 0.07$ & $1.11 \pm 0.01$ & $0.61 \pm 0.08$ & $0.352 \pm 0.006$ & 0.96 \\
\hline $47.6 \pm 0.33$ & $2.33 \pm 0.02$ & $0.56 \pm 0.30$ & $0.44 \pm 0.02$ & 1.00 \\
\hline $45.5 \pm 0.20$ & $2.93 \pm 0.04$ & $0.55 \pm 0.04$ & $0.58 \pm 0.02$ & 1.13 \\
\hline $41.3 \pm 0.42$ & $4.67 \pm 0.04$ & $0.40 \pm 0.13$ & $0.56 \pm 0.01$ & 0.96 \\
\hline $36.1 \pm 0.43$ & $7.05 \pm 0.03$ & $0.33 \pm 0.10$ & $0.67 \pm 0.12$ & 1.00 \\
\hline $31.4 \pm 0.50$ & $9.77 \pm 0.04$ & $0.25 \pm 0.12$ & $0.79 \pm 0.04$ & 1.04 \\
\hline $26.9 \pm 0.09$ & $11.67 \pm 0.07$ & $0.19 \pm 0.02$ & $0.93 \pm 0.02$ & 1.12 \\
\hline $21.1 \pm 0.06$ & $13.7 \pm 0.17$ & $0.13 \pm 0.02$ & $0.89 \pm 0.07$ & 1.02 \\
\hline $16.29 \pm 0.05$ & $16.57 \pm 0.07$ & $0.09 \pm 0.04$ & $1.01 \pm 0.09$ & 1.10 \\
\hline $11.17 \pm 0.05$ & $19.54 \pm 0.09$ & $0.10 \pm 0.01$ & $0.90 \pm 0.02$ & 1.00 \\
\hline
\end{tabular}

5000 atomic absorption spectrophotometer. Fisher Certified Reference Solutions were used in the preparation of all standard curves.

\section{Clay Slurry Analysis}

Three of the replicate clay slurries in a exchange experiment were mixed with $0.1 \mathrm{~kg}$ of $1 M \mathrm{NH}_{4} \mathrm{C}_{2} \mathrm{H}_{3} \mathrm{O}_{2}$, shaken 15 min on a tray shaker, and either centrifuged or allowed to stand until the solid phase settled. The supernatant solution was analyzed for $\mathrm{Na}$ by flame emission and $\mathrm{Ca}$ or $\mathrm{Mg}$ by flame absorption, as described above, except that the standard solutions contained $\mathrm{NH}_{4} \mathrm{C}_{2} \mathrm{H}_{3} \mathrm{O}_{2}$ at the same concentration as in the analyzed solutions. This procedure was found to be more convenient but no less accurate for recovering $\mathrm{Na}, \mathrm{Ca}$ and $\mathrm{Mg}$ from the clay slurry than the multiple-extraction procedure described by Sposito et al. (1981).

Three of the replicate clay slurries in an exchange experiment were oven-dried for $48 \mathrm{~h}$ at $60^{\circ} \mathrm{C}$. Each of these samples then was cooled $3 \mathrm{~h}$ in a vacuum dessicator over $\mathrm{P}_{2} \mathrm{O}_{5}$ and weighed. The mass difference after drying was set equal to the mass of water in the slurry sample.

\section{Data Analysis}

The surface excesses of $\mathrm{Na}, \mathrm{Ca}$, and $\mathrm{Mg}$ were calculated as described by Sposito et al. (1981), with the appropriate relative molecular masses of $\mathrm{NaClO}_{4}, \mathrm{Ca}\left(\mathrm{ClO}_{4}\right)_{2}, \mathrm{Mg}\left(\mathrm{ClO}_{4}\right)_{2}, \mathrm{NaCl}$, $\mathrm{CaCl}_{2}$, or $\mathrm{MgCl}_{2}$ introduced into the equation for the parameter $D$, the mass of water in $1 \mathrm{~kg}$ of supernatant solution. The apparent total adsorbed metal charge, $Q$, was calculated according to the expression

$$
Q=\Gamma_{\mathrm{Na}}+2 \Gamma_{\mathrm{M}} \equiv q_{\mathrm{Na}}+q_{\mathrm{M}},
$$

where $\Gamma$ is a surface excess in moles of adsorbed metal per kilogram of clay, $q$ is the corresponding number of moles of adsorbed metal charge per kilogram of clay, and $\mathrm{M}=\mathrm{Ca}$ or $\mathrm{Mg}$.

Table 4-Experimental data on $\mathrm{Na}-\mathrm{Ca}$ exchange at $298 \mathrm{~K}$ on Wyoming bentonite in a $0.05 M$ chloride background.

\begin{tabular}{|c|c|c|c|c|c|}
\hline \multicolumn{2}{|c|}{$c_{\mathrm{Na}}$} & $c_{\mathrm{Ca}}$ & $q_{\mathrm{Na}}$ & $q_{\mathrm{Ca}}$ & $Q$ \\
\hline \multicolumn{3}{|c|}{$\mathrm{mol} \mathrm{kg}^{-1} \times 10^{3} \longrightarrow$} & \multicolumn{3}{|c|}{$-\mathrm{mol}_{c} \mathrm{~kg}$} \\
\hline 52.8 & \pm 0.14 & $<10^{-4}$ & $0.95 \pm 0.08$ & $<10^{-3}$ & 0.95 \\
\hline 48.4 & \pm 0.14 & $1.04 \pm 0.00$ & $0.58 \pm 0.08$ & $0.321 \pm 0.004$ & 0.91 \\
\hline 48.4 & \pm 0.26 & $1.98 \pm 0.01$ & $0.44 \pm 0.08$ & $0.558 \pm 0.009$ & 1.00 \\
\hline 43.6 & \pm 0.19 & $3.05 \pm 0.01$ & $0.34 \pm 0.06$ & $0.64 \pm 0.01$ & 0.98 \\
\hline 40.8 & \pm 0.13 & $4.32 \pm 0.01$ & $0.31 \pm 0.04$ & $0.747 \pm 0.009$ & 1.06 \\
\hline 35.64 & \pm 0.06 & $6.30 \pm 0.01$ & $0.23 \pm 0.07$ & $0.88 \pm 0.01$ & 1.11 \\
\hline 29.60 & \pm 0.06 & $8.63 \pm 0$ & $0.22 \pm 0.04$ & $0.80 \pm 0.03$ & 1.02 \\
\hline 25.55 & \pm 0.07 & $11.09 \pm 0.08$ & $0.08 \pm 0.04$ & $0.88 \pm 0.02$ & 0.96 \\
\hline 20.77 & \pm 0.05 & $13.07 \pm 0.01$ & $0.06 \pm 0.03$ & $1.02 \pm 0.03$ & 1.08 \\
\hline 15.96 & \pm 0.09 & $15.30 \pm 0.02$ & $0.06 \pm 0.04$ & $1.14 \pm 0.04$ & 1.20 \\
\hline 11.45 & \pm 0.05 & $17.62 \pm 0.03$ & $0.10 \pm 0.02$ & $1.18 \pm 0.02$ & 1.28 \\
\hline 5.69 & \pm 0.04 & $19.92 \pm 0.09$ & $0.05 \pm 0.01$ & $1.20 \pm 0.04$ & 1.25 \\
\hline
\end{tabular}

Table 3-Experimental data on $\mathrm{Na}^{+}-\mathrm{Mg}^{2+}$ exchange at $298 \mathrm{~K}$ on Wyoming bentonite in a $0.05 \mathrm{M}$ perchlorate background.

\begin{tabular}{|c|c|c|c|c|c|}
\hline \multicolumn{2}{|c|}{$c_{\mathrm{Na}}$} & $x_{\mathrm{Mg}}$ & $q_{\mathrm{Na}}$ & $q_{\mathrm{Mg}}$ & $Q$ \\
\hline \multicolumn{3}{|c|}{$\mathrm{mol} \mathrm{kg}^{-1} \times 10^{3}$} & & $\mathrm{nol}_{c} \mathrm{~kg}^{-1}$ & \\
\hline 51.3 & \pm 0.24 & $<10^{-5}$ & $0.84 \pm 0.25$ & $<10^{-4}$ & 0.84 \\
\hline 49.5 & \pm 0.12 & $1.17 \pm 0.01$ & $0.53 \pm 0.09$ & $0.280 \pm 0.007$ & 0.81 \\
\hline 47.4 & \pm 0.33 & $2.34 \pm 0.01$ & $0.30 \pm 0.17$ & $0.45 \pm 0.02$ & 0.75 \\
\hline 44.0 & \pm 0.13 & $7.00 \pm 0.05$ & $0.22 \pm 0.08$ & $0.70 \pm 0.04$ & 0.92 \\
\hline 38.3 & \pm 0.21 & $9.4 \pm 0.56$ & $0.23 \pm 0.14$ & $0.86 \pm 0.12$ & 1.09 \\
\hline 34.0 & \pm 0.10 & $12.44 \pm 0.05$ & $0.10 \pm 0.02$ & $0.74 \pm 0.03$ & 0.84 \\
\hline 29.05 & \pm 0.04 & $14.9 \pm 0.11$ & $0.08 \pm 0.04$ & $0.74 \pm 0.07$ & 0.82 \\
\hline 23.68 & \pm 0.08 & $17.4 \pm 0.24$ & $0.06 \pm 0.02$ & $0.78 \pm 0.05$ & 0.84 \\
\hline 18.5 & \pm 0.17 & $19.65 \pm 0.08$ & $0.06 \pm 0.03$ & $0.95 \pm 0.02$ & 1.01 \\
\hline
\end{tabular}

\section{RESULTS AND DISCUSSION}

The primary laboratory data on the exchange experiments carried out in a perchlorate ionic background appear in Tables 2 and 3 . In these tables, $c$ refers to an equilibrium concentration in the aqueous solution phase and $q$ is equal to the product $Z \Gamma$, where $Z$ is the oxidation number of the cation. Thus the units of $q$ are moles of charge (formerly called equivalents) per kilogram of clay (Thien and Oster, 1981). The fifth column in Tables 2 and 3 indicates that, in the perchlorate background, the total adsorbed metal charge showed no tendency to increase with increasing $q_{\mathrm{M}}(\mathrm{M}=\mathrm{Ca}$ or $\mathrm{Mg})$. In the case of $\mathrm{Na}^{+}-\mathrm{Ca}^{2+}$ exchange, the mean value of $Q$ was 1.03 $\pm 0.05 \mathrm{~mol}_{c} \mathrm{~kg}^{-1}$ and for $\mathrm{Na}^{+}-\mathrm{Mg}^{2+}$ exchange it was $0.9 \pm 0.1 \mathrm{~mol}_{c} \mathrm{~kg}^{-1}$. These values are in agreement with CECs reported typically for Wyoming bentonites (Weaver and Pollard, 1973, Chap. 5) and with the value $Q=0.92$ $\pm 0.05 \mathrm{~mol}_{c} \mathrm{~kg}^{-1}$ determined by Sposito et al. (1981) in their study of $\mathrm{Na}^{+}-\mathrm{Cu}^{2+}$ exchange on Wyoming bentonite in a perchlorate background.

Tables 4 and 5 list the primary data obtained in the exchange experiments carried out in a chloride ionic background. The values of $Q$ in these experiments show a tendency to increase gradually with $q_{\mathrm{M}}(\mathrm{M}=\mathrm{Ca}$ or $\mathrm{Mg})$. The apparent total adsorbed metal charge approaches $1.3 \mathrm{~mol}_{c} \mathrm{~kg}^{-1}$, in the case of $\mathrm{Na}-\mathrm{Ca}$ exchange, and $1.25 \mathrm{~mol}_{c} \mathrm{~kg}^{-1}$, in the case of $\mathrm{Na}-\mathrm{Mg}$ exchange, as the clay becomes saturated with the bivalent metal cation. The values of $Q$ in Table 4 compare well with the $Q$-values reported by Shainberg et al. (1980, Table 2) for $\mathrm{Na}-\mathrm{Ca}$ exchange on Wyoming bentonite in a chloride background maintained at $0.06 M$.

On the hypothesis of Sposito et al. (1981), Na-Ca and $\mathrm{Na}-\mathrm{Mg}$ exchange in a chloride background involves the ternary cation system, $\mathrm{Na}^{+}-\mathrm{MCl}^{+}-\mathrm{M}^{2+}(\mathrm{M}=\mathrm{Ca}$ or

Table 5-Experimental data on $\mathrm{Na}-\mathrm{Mg}$ exchange at $298 \mathrm{~K}$ on Wyoming bentonite in a $0.05 M$ chloride background.

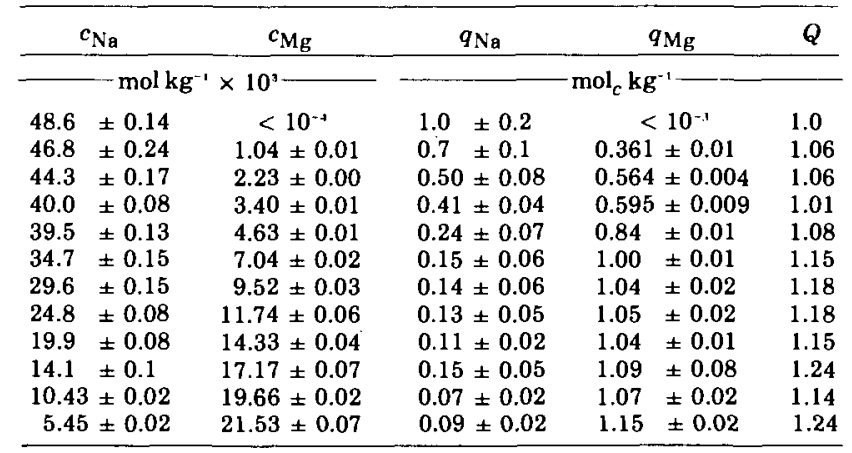


Table 6-Concentrations of $\mathrm{Ca}^{2+}$ and $\mathrm{CaCl}^{+}$calculated by GEOCHEM and values of $q_{\mathrm{Ca}^{2+}}$ and $q_{\mathrm{CaCl}}$ calculated with Eq. [2] and Eq. [4].

\begin{tabular}{rccccc}
\hline$c_{\mathrm{Ca}} \dagger$ & {$\left[\mathrm{Ca}^{2+}\right]$} & {$\left[\mathrm{CaCl}^{+}\right]$} & & $q_{\mathrm{Ca}^{2+}}$ & $q_{\mathrm{CaCl}^{*}}$ \\
\hline & $\mathrm{mol} \mathrm{kg}^{-1} \times 10^{3}$ & & & & \\
\cline { 1 - 1 } & 0.984 & 0.056 & & 0.295 & 0.01 \\
1.04 & 1.87 & 0.110 & 0.415 & 0.03 \\
1.98 & 2.89 & 0.159 & & 0.548 & 0.04 \\
3.05 & 4.10 & 0.216 & 0.637 & 0.06 \\
4.32 & 6.00 & 0.302 & 0.690 & 0.09 \\
6.30 & 8.21 & 0.423 & 0.665 & 0.13 \\
8.63 & 10.55 & 0.543 & 0.649 & 0.17 \\
11.09 & 12.46 & 0.614 & 0.643 & 0.20 \\
13.07 & 14.60 & 0.704 & 0.625 & 0.24 \\
15.30 & 16.83 & 0.793 & 0.609 & 0.28 \\
17.62 & 19.06 & 0.857 & 0.598 & 0.32 \\
19.92 & & &
\end{tabular}

$\dagger$ Data from Table 4.

$\mathrm{Mg}$ ). Therefore, the total adsorbed metal charge is given by the equation

$$
Q_{0}=q_{\mathrm{Na}+}+q_{\mathrm{MCl}+}+q_{\mathrm{M}^{2}+}(\mathrm{M}=\mathrm{Ca} \text { or } \mathrm{Mg}) .
$$

The value of the parameter $Q_{0}$ can be measured, for example, by determining $Q$ in an exchange experiment conducted in a perchlorate background or by extrapolating $Q$ measured in an exchange experiment conducted in a chloride background to the condition of vanishing $q_{\mathrm{M}}(\mathrm{M}=\mathrm{Ca}$ or $\mathrm{Mg})$. Thus $Q_{0}$ is to be distinguished clearly from $Q$ in exchange experiments done in a chloride background:

$$
\begin{aligned}
& Q=q_{\mathrm{Na}}+q_{\mathrm{M}} \\
& =q_{\mathrm{Na}+}+2 q_{\mathrm{MCl}+}+q_{\mathrm{M}^{2+}} \quad(\mathrm{M}=\mathrm{Ca} \text { or } \mathrm{Mg}), \text { [3] }
\end{aligned}
$$

since $q_{\mathrm{M}} \equiv 2 \Gamma_{\mathrm{M}}=2 \Gamma_{\mathrm{M} 2+}+2 \Gamma_{\mathrm{MCl}}=q_{\mathrm{M}^{2+}}+2 q_{\mathrm{MCl}+}$ by hypothesis. It follows from Eq. [2] and Eq. [3] that

$$
q_{\mathrm{MCl}+}=Q-Q_{0} \quad(\mathrm{M}=\mathrm{Ca} \text { or } \mathrm{Mg}) \text {. }
$$

The observed increase in $Q$ with $q_{\mathrm{M}}(\mathrm{M}=\mathrm{Ca}$ or $\mathrm{Mg})$ in Tables 4 and 5 thus is considered to be an artifact caused by attributing a valence of $2+$ to all of the adsorbed calcium or magnesium, whereas part of it (the adsorbed complex, $\mathrm{MCl}^{+}$) actually is a monovalent species.

Tables 6 and 7 list the values of $q_{\mathrm{M}^{2}+}$ and $q_{\mathrm{MCl}}+\mathrm{cal}-$ culated with Eq. [2] and Eq. [4]. To facilitate the calculations, the experimental $Q$ and $q_{\mathrm{Na}}$ data in Tables 4 and 5 were fit accurately to smooth curves as functions of the charge fraction (equivalent fraction) of either $\mathrm{Ca}$ or $\mathrm{Mg}$ in the aqueous solution phase by means of polynomial regression. The value of $Q_{0}$ was taken to be equal to the regression equation estimate of $Q$ when the clay was $\mathrm{Na}$-saturated. These estimates were $Q_{0}=0.96$ mol $_{c} \mathrm{~kg}^{-1}$ for $\mathrm{Na}-\mathrm{Ca}$ exchange and $Q_{0}=1.04 \mathrm{~mol}_{c} \mathrm{~kg}^{-1}$ for $\mathrm{Na}-\mathrm{Mg}$ exchange. The composition of the aqueous solution phase in each exchange experiment (Tables 4 and 5) was input into the computer program GEOCHEM (Sposito and Mattigod, 1980) to calculate the molal concentrations of $\mathrm{M}^{2+}$ and $\mathrm{MCl}^{+}(\mathrm{M}=\mathrm{Ca}$ or $\mathrm{Mg}$ ) according to the stability constants in Table 1 . These concentrations are listed in Tables 6 and 7 next to the corresponding values of $q_{\mathrm{M} 2+}$ and $q_{\mathrm{MCl}+}$.

Exchange isotherms for $\mathrm{CaCl}^{+}$and $\mathrm{MgCl}^{+}$based on the data in Tables 6 and 7 are shown in Fig. 1. The plotted variables in the figure are the charge fractions (Sposito, 1981, Chap. 5)

\begin{tabular}{|c|c|c|c|c|}
\hline$c_{\mathrm{Mg}^{\dagger}}$ & {$\left[\mathrm{Mg}^{2+}\right]$} & {$\left[\mathrm{MgCl}^{+}\right]$} & $q_{\mathbf{M g}^{2+}}$ & $q_{\mathrm{MgCl}}$ \\
\hline 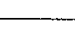 & \multicolumn{2}{|c|}{$\mathrm{mol} \mathrm{kg-1} \times 10^{3} \longrightarrow$} & \multicolumn{2}{|c|}{$\mathrm{mol}_{c} \mathbf{k g}^{-1}$} \\
\hline 1.04 & 0.994 & 0.046 & 0.282 & 0.01 \\
\hline 2.23 & 2.13 & 0.098 & 0.485 & 0.02 \\
\hline 3.40 & 3.25 & 0.146 & 0.657 & 0.03 \\
\hline 4.63 & 4.42 & 0.208 & 0.754 & 0.04 \\
\hline 7.04 & 6.72 & 0.317 & 0.820 & 0.06 \\
\hline 9.52 & 9.13 & 0.390 & 0.824 & 0.08 \\
\hline 11.74 & 11.27 & 0.470 & 0.817 & 0.10 \\
\hline 14.33 & 13.74 & 0.586 & 0.812 & 0.12 \\
\hline 17.17 & 16.47 & 0.704 & 0.808 & 0.14 \\
\hline 19.66 & 18.83 & 0.826 & 0.790 & 0.16 \\
\hline 21.53 & 20.65 & 0.883 & 0.794 & 0.18 \\
\hline
\end{tabular}

Table 7-Concentrations of $\mathrm{Mg}^{2+}$ and $\mathrm{MgCl}^{+}$calculated by GEOCHEM and values of $q_{\mathrm{M}^{2+}}$ and $q_{\mathrm{MgCl}}$. calculated with Eq. [2] and Eq. [4].

† Data from Table 5 .

$$
E_{A}=\frac{q_{A}}{Q_{0}} \quad \tilde{E}_{A}=\frac{Z_{A}\left[A^{Z_{A^{+}}}\right]}{T N},
$$

where $A$ is a cation of valence $Z_{A}$ and $T N$ is the total cation normality in the aqueous solution phase. Figure 1 indicates that montmorillonite has a greater affinity for $\mathrm{CaCl}^{+}$than for $\mathrm{MgCl}^{+}$under the conditions of the exchange experiments in the present study. However, the affinity of the clay for both complexes is relatively high, since $\mathrm{MCl}^{+}$adsorption accounts for one-fifth to one-third of $Q_{0}$ when the concentration of this species contributes only about $2 \%$ to the total cation normality in the aqueous solution phase.

Exchange isotherms for $\mathrm{Ca}^{2+}$ and $\mathrm{Mg}^{2+}$ based on the data in Tables 2, 3, 6, and 7 are shown in Fig. 2 and 3. These isotherms are identical (within the experimental precision of $\pm 10 \%$ ) in both perchlorate and chloride background media until $\mathrm{Ca}^{2+}$ or $\mathrm{Mg}^{2+}$ adsorption accounts for 70 to $80 \%$ of $Q_{0}$. Thereafter, the charge fraction of the free metal cation on the clay, $E_{\mathrm{M} 2+}$, tends to decrease slightly in the chloride background, whereas it continues to increase in the perchlorate background.

The exchange behavior illustrated in Fig. 1 to 3 can be understood in terms of the "demixing" concepts discussed by Shainberg et al. (1980). As $E_{\mathrm{M} 2+}$ increases from zero to about 0.7 in either background ionic medium, the free metal cation, $\mathrm{M}^{2+}$, is the preferred species for adsorption because it promotes the formation of sta-

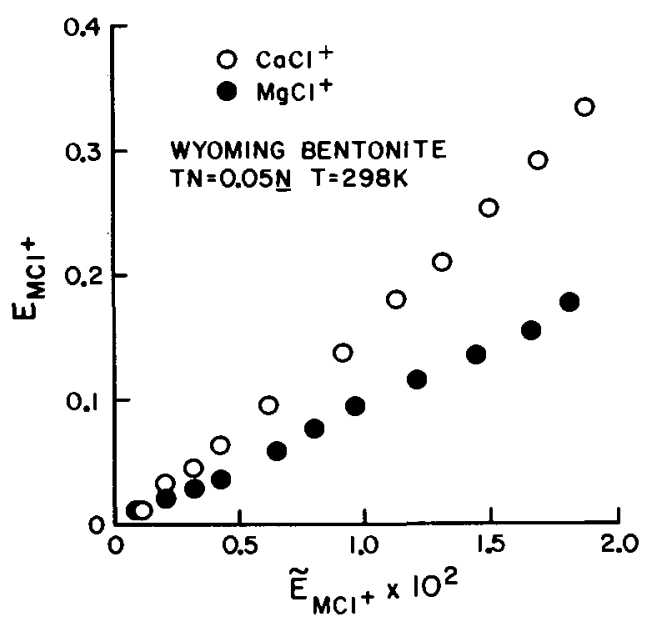

Fig. 1-Exchange isotherms for $\mathrm{CaCl}^{+}$and $\mathrm{MgCl}^{+}$on Wyoming bentonite $\left(\mathrm{Na}^{+}-\mathrm{MCI}^{+}-\mathrm{M}^{2+}\right.$ system). 


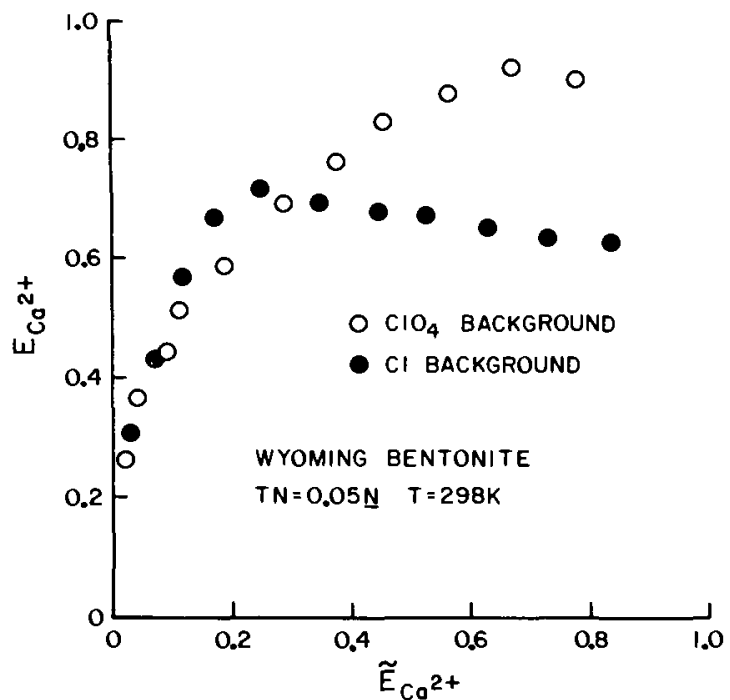

Fig. 2-Exchange isotherms for $\mathrm{Ca}^{2+}$ on Wyoming bentonite in perchlorate and chloride backgrounds ( $\mathrm{Na}-\mathrm{Ca}$ exchange).

ble quasicrystals in the clay suspension. After the quasicrystals have formed $\left(E_{\mathrm{M} 2+}>0.7\right)$, the principal remaining sites for cation exchange are on the external surfaces of the quasicrystals where, in general, bivalent species are much less preferred because of stereochemical and electric potential considerations (Shainberg et al., 1980). In a perchlorate background, the adsorption of the free metal cation on the external surfaces can continue to take place, despite the decline in preference, simply by mass action: As the concentration of $\mathrm{M}^{2+}$ is increased in the aqueous solution phase, there are more bivalent cations available to displace adsorbed $\mathrm{Na}^{+}$. In a chloride background, however, the free metal cation has the option to form the monovalent species, $\mathrm{MCl}^{+}$, which then can be a potent competitor with $\mathrm{Na}^{+}$for the external surface sites. Therefore, as the concentration of $\mathrm{MCl}_{2}$ (aq) is increased, the concentration of $\mathrm{MCl}^{+}$(aq) increases, and this species is adsorbed in preference to the free metal cation. The effect of this adsorption preference is to make the sum $\left(q_{\mathrm{Na}}++q_{\mathrm{MCl}+}\right)$ equal to a constant for $q_{\mathrm{M}}>0.8 \mathrm{~mol}_{c} \mathrm{~kg}^{-1}$ (Cf. Tables 4 and 6 or Tables 5 and 7) and to cause the exchange isotherm for $\mathrm{M}^{2+}(\mathrm{M}=\mathrm{Ca}$ or $\mathrm{Mg})$ in the chloride background to level off (Fig. 2 and 3).

\section{CONCLUSIONS}

Sodium-calcium and sodium-magnesium exchange reactions on montmorillonite in the presence of chloride ions in the aqueous solution phase can be expected to involve the ternary cation system, $\mathrm{Na}^{+}-\mathrm{MCl}^{+}-\mathrm{M}^{2+}(\mathrm{M}$ $=\mathrm{Ca}$ or $\mathrm{Mg}$ ). When the charge fraction of the free bivalent metal cation on the clay is $<0.7$, the amount of the monovalent complex, $\mathrm{MCl}^{+}$, on the clay surface will be small, both because its concentration in the aqueous solution phase is small and because, like $\mathrm{Na}^{+}$, it cannot compete with $\mathrm{M}^{2+}$ to promote the formation of stable montmorillonite quasicrystals. When the concentration of calcium in the aqueous solution phase rises above a value sufficient to saturate the internal surfaces of the quasicrystals formed with $\mathrm{M}^{2+}$ (at which time $E_{\mathrm{M} 2+} \approx 0.7$ ), the external surfaces of the quasicrystals become the principal sites for $\mathrm{Na}^{+}$replacement and the

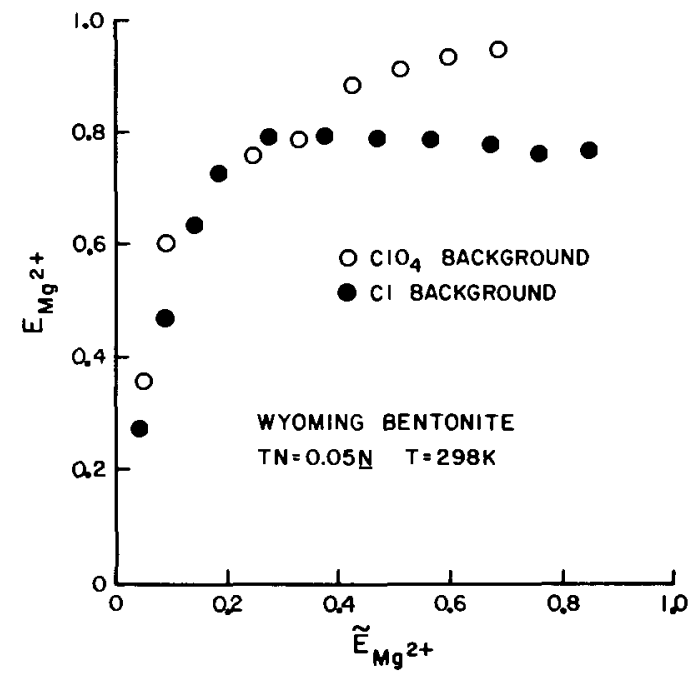

Fig. 3-Exchange isotherms for $\mathrm{Mg}^{2+}$ on Wyoming bentonite in perchlorate and chloride backgrounds ( $\mathrm{Na}-\mathrm{Mg}$ exchange).

adsorption of $\mathrm{MCl}^{+}$by the clay is favored over that of $\mathrm{M}^{2+}$ because of the well-known preference of these external surfaces for monovalent cations. According to this picture of the exchange process, a $\mathrm{Ca}$ - or a $\mathrm{Mg}$-montmorillonite suspension in a chloride background consists of quasicrystals with the monovalent complexes $\mathrm{MCl}^{+}$ adsorbed primarily on the external surfaces and free bivalent metal cations adsorbed primarily on the internal surfaces.

\section{ACKNOWLEDGMENTS}

Gratitude is expressed to T.J. Ganje, W. Smith, and C.S. LeVesque for technical assistance. The research reported in this paper was supported in part by the Kearney Foundation of Soil Science and in part by a grant-in-aid to L. Charlet from the Graduate Division of the University of California, Riverside. Gratitude also is expressed for a research fellowship to Dr. C. Jouany from the French Ministry of Foreign Affairs.

\section{REFERENCES}

1. Babcock, K.L., and R.K. Schulz. 1963. Effect of anions on the sodium-calcium exchange in soils. Soil. Sci. Soc. Am. J. 27:630632.

2. Deist, J., and O. Talibudeen. 1967. Thermodynamics of $\mathrm{K}-\mathrm{Ca}$ exchange in soils. J. Soil Sci. 18:138-148,

3. Hester, R.E., and R.A. Plane. 1964. A Raman spectrophotometric comparison of interionic association in aqueous solutions of metal nitrates, sulfates, and perchlorates. Inorg. Chem. 3:769-770.

4. Jensen, H.E. 1973. Potassium-calcium exchange equilibria on a montmorillonite and a kaolinite clay. 1. A test on the Argersinger thermodynamic approach. Agrochimica 17:181-190.

5. Jensen, H.E., and K.L. Babcock. 1973. Cation-exchange equilibria on a Yolo loam. Hilgardia 41:475-488.

6. Johnson, K.S. 1979. Ion association and activity coefficients in electrolyte solutions. Ph.D. Dissertation, Oregon State University.

7. Johnson, K.S. 1981. The calculation of ion pair diffusion coefficients: a comment. Mar. Chem. 10:195-208.

8. Laudelout, H., R. Van Bladel, G.H. Bolt, and A.L. Page. 1968. Thermodynamics of heterovalent exchange reactions in a montmorillonite clay. Trans. Faraday Soc. 64:1477-1488.

9. Levy, R., and D. Hillel. 1968. Thermodynamic equilibrium constants of sodium-calcium exchange in some Israel soils. Soil Sci. 106:393-398.

10. Maes, A., and A. Cremers. 1977. Charge density effects in ion exchange. Part 1. Heterovalent exchange equilibria. J. Chem. Soc. Faraday I 73:1807-1814.

11. Maes, A., P. Peigneur, and A. Cremers. 1976. Thermodynamics of transition metal ion exchange in montmorillonite. Proc. Int. Clay Conf. 1975:319-329.

12. Schwertmann, U. 1962. Die selektive Kationensorption der Tonfraktion einiger Boden aus Sedimenten. Z. Pflanzenernahr. Dung. 
Bodenkunde 97:9-25.

13. Shainberg, I., J.D. Oster, and J.D. Wood. 1980. Sodium/calcium exchange in montmorillonite and illite suspensions. Soil. Sci. Soc. Am. J. 44:960-964.

14. Smith, R.M., and A.E. Martell. 1976. Critical stability constants. Vol. 4: Inorganic complexes. Plenum Press, New York.

15. Sposito, G. 1981. The thermodynamics of soil solutions. Oxford Univ. Press, Oxford, U.K.

16. Sposito, G., and K.M. Holtzclaw. 1979. Copper(II) complexation by fulvic acid extracted from sewage sludge as influenced by nitrate versus perchlorate background ionic media. Soil. Sci. Soc. Am. J. 43:47-51.

17. Sposito, G., K.M. Holtzclaw, C.T. Johnston, and C.S. LeVesque. 1981. Thermodynamics of sodium-copper exchange on Wyoming bentonite at 298 K. Soil. Sci. Soc. Am. J. 45:1079-1084.

18. Sposito, G., and S.V Mattigod. 1980. GEOCHEM: a computer program for the calculation of chemical equilibria in soil solutions and other natural water systems. Kearney Foundation of Soil Science, University of California.

19. Thien, S.J., and J.D. Oster. 1981. The international system of units and its particular application to soil chemistry. J. Agron. Ed. 10:6270.

20. Van Bladel, R. G. Gaviria, and H. Laudelout. 1973. A comparison of the thermodynamic, double layer theory and empirical studies of the $\mathrm{Na}-\mathrm{Ca}$ exchange equilibria in clay water systems. Proc. Int Clay Conf. 1972:385-398.

2I. Van Bladel, R., and H.R. Gheyi. 1980. Thermodynamic study of calcium-sodium and calcium-magnesium exchange in calcareous soils. Soil. Sci. Soc. Am. J. 44:938-942.

22. Van Bladel, R., and R. Menzel 1969. A thermodynamic study of sodium-strontium exchange on Wyoming bentonite. Proc. Int. Clay Conf. I:619-634.

23. Weaver, C.E., and L.D. Pollard. 1973. The chemistry of clay minerals. Elsevier Sci. Publ. Co., Amsterdam. 